\title{
Promoção Juntou Ganhou: uma experiência gamificada para o engajamento de estudantes de Ensino Médio
}

\author{
Cláudia Borges Coutinho \\ Universidade Federal do Estado da Bahia (UFBA) \\ claudiabcoutegmail.com
}

\begin{abstract}
Teaching Computer Science in integrated high school classes has a lot of challenges. Among them the lack of student engagement for this learning. In an attempt to modify this situation, an approach using gamification was thought of. This paper describes a pedagogical experience of an applied gamification proposal as an active learning strategy in professional high school classes. The purpose of the approach was to promote student engagement. For this, this approach based on promotions like "You collected, you won", where students needed to fulfill missions and collect stamps to exchange for gifts that aimed to stimulate the development of good practices and enable the development of their own learning.
\end{abstract}

\begin{abstract}
Resumo. O ensino de Computação em turmas de Ensino Médio Integrado enfrenta diversos desafios, dentre estes está a falta de engajamento dos estudantes no processo de ensino e aprendizagem. Na tentativa de modificar essa situação fora pensada uma abordagem pedagógica utilizando-se de mecanismos de gamificação. Este texto descreve a experiência pedagógica de uma proposta de gamificação aplicada como estratégia para promover o engajamento dos estudantes. Para isso foi utilizada uma abordagem baseada nas promoções "Juntou Ganhou", em que os estudantes precisavam cumprir missões e colecionar selos para trocar por brindes que tinham como objetivo estimular o desenvolvimento de boas práticas de disciplina e comprometimento e assim, possibilitar o desenvolvimento do seu próprio aprendizado.
\end{abstract}

\section{Introdução}

Huizinga (1943, p. 3), em sua obra Homo Ludens diz que o "jogo é fato mais antigo que a cultura, pois esta, mesmo em suas definições mais rigorosas, pressupõe sempre a sociedade humana". Assim, desde os tempos primórdios da humanidade há um fascínio latente pelo universo dos jogos. É fácil encontrar imagens e literaturas que mostram os jogos presentes 
VIII Congresso Brasileiro de Informática na Educação (CBIE 2019)

Anais dos Workshops do VIII Congresso Brasileiro de Informática na Educação (WCBIE 2019)

nas nossas vidas desde as mais antigas civilizações. Por meio deles ocorria a socialização, interação e aprendizagem conjunta entre adultos e crianças.

Ainda que muitos atribuam às crianças o termo lúdico ou o ato de brincar, as pesquisas sobre jogos (atividade de entretenimento que prevê desafios, regras e pontuação) e games (jogos em ambiente digital), mostra que essa não é uma particularidade exclusiva das crianças. Cada vez mais aumenta o número de adultos que jogam e, com o advento da computação, da internet e dos dispositivos móveis, os games vêm se tornando uma das maiores indústrias de entretenimento do mundo (ALVES, 2014. p.19); consequentemente, umas das mais rentáveis também.

Segundo Yu Kai-Chou (2014), as pessoas encontram diversas motivações para jogar. Motivações como fazer parte de algo grandioso, realizar missões, desenvolver habilidades, ganhar status ou colecionar bens são algumas das motivações que levam as pessoas a ficar por horas a fio tentando resolver dada situação ou subir de nível em um jogo.

Vygotsky (1998) traz a importância dos jogos e da ludicidade na aprendizagem, assim, cresceram-se os estudos sobre os impactos dos jogos na aprendizagem e logo os jogos começaram a fazer parte da aprendizagem na escola.. Eis que surgem iniciativas como os jogos didáticos ou jogos educativos, jogos sérios (jogos com a finalidade não apenas de entreter, mas também ensinar); surgem as propostas GBL - Game Based Learning, ou Aprendizagem Baseada em Games e agora, como proposta de educação inovadora, surge a gamificação.

Do inglês gamification, a gamificação já é uma prática adotada e de sucesso no universo mercadológico e empresarial. Faz parte do nosso dia a dia, com as promoções “Compre 10 e ganhe o próximo grátis", com os cartões de fidelidade, com os programas para juntar milhas aéreas e tantas outras iniciativas que estão ao nosso redor.

A gamificação na educação é mais uma tendência que surge no âmbito das aprendizagens ativas (Silva et al. 2019). Metodologias essas que tiram os estudantes da posição de receptor de conteúdos, colocando-os como principal participante da sua aprendizagem. Assim, a gamificação está entre as propostas baseadas em experimentações lúdicas, em experiências "mão na massa", hackerspaces, educação maker, em que todas têm 
VIII Congresso Brasileiro de Informática na Educação (CBIE 2019)

Anais dos Workshops do VIII Congresso Brasileiro de Informática na Educação (WCBIE 2019)

a finalidade de colocar o estudante como participante ativo, a fim de estimular e propiciar experiências cognitivas para os estudantes.

Gamificação é o uso de elementos de jogo e técnicas de design de jogos em contextos não-jogo. (WERBACH; HUNTER, 2012), assim, a gamificação não trata de usar ou criar jogos ou games para um determinado propósito, mas da utilização de elementos dos jogos, como os mecanismos, narrativas, sistemas de premiação, regras e desafios de forma a engajar pessoas para atingir um objetivo. Outra característica importante é que na gamificação as premiações acontecem no mundo real, como um brinde, o desenvolvimento de uma habilidade, enquanto que nos jogos e games as premiações ou a coleção de bens acontecem apenas num mundo virtual ou fictício.

Assim, na perspectiva de contribuir com outros estudos na área da gamificação na educação, este artigo tem por finalidade relatar a experiência em uma turma de ensino médio profissionalizante (em Informática), em que se pretendia alcançar o engajamento da turma para a adoção de boas práticas e consequentemente, uma postura mais comprometida com os seus estudos e construção do seu aprendizado, a priori, para o componente curricular de Banco de Dados.

A proposta idealizada foi baseada nas promoções "junte os selos e ganhe um brinde", tão comum no universo comercial. Os estudantes precisavam cumprir tarefas para ganhar selos e, ao colecioná-los em determinada categoria, era possível ganhar um brinde já determinado.

Este relato está organizado em mais 3(três) seções: Metodologia, onde está a descrição da experiência e os sujeitos envolvidos; Resultados e Discussões com algumas verificações importantes para o trabalho docente e, por fim, as Considerações Finais.

\section{Metodologia}

A proposta de gamificação foi aplicada em turmas do $3^{\circ}$ ano do Ensino Médio Profissionalizante do componente curricular de Banco de Dados. As turmas compreendem jovens na faixa etária entre 16 e 18 anos. Foram 3 (três) turmas heterogêneas dos cursos de Manutenção e Suporte de Computadores, Redes de Computadores e Suporte Técnico em Informática. No total, foram 56 estudantes envolvidos na proposta. 
VIII Congresso Brasileiro de Informática na Educação (CBIE 2019)

Anais dos Workshops do VIII Congresso Brasileiro de Informática na Educação (WCBIE 2019)

A proposta aqui tratada não tinha como finalidade melhorar o aprendizado dos estudantes, ainda que isso fosse uma consequência esperada. O principal objetivo foi a adoção de uma postura mais responsável e comprometida na resolução e entrega de atividades, de estimular a assiduidade e pontualidade nas aulas e a participação nas atividades desenvolvidas na sala de aula virtual da turma. Boas práticas que poderiam resultar na construção do seu próprio aprendizado no componente curricular de Banco de Dados.

Para esta proposta foi criada uma cartela (vide link http://bit.ly/2pJ0XDl) onde os estudantes colariam os selos conseguidos ao realizar determinada missão. Nela também estavam descritos os brindes e quais correspondiam a cada missão, as regras e a descrição de cada missão.
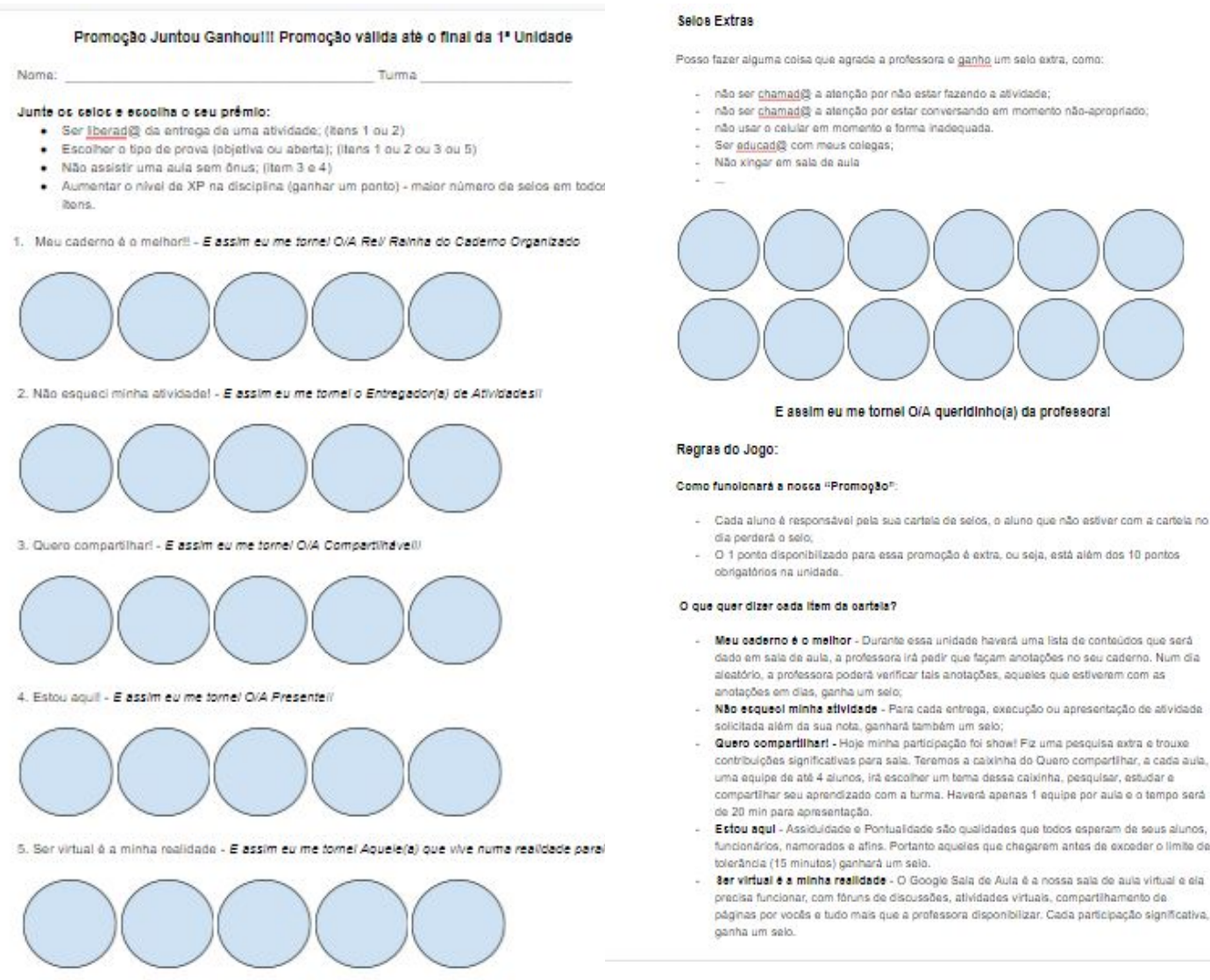

Como funolonars a noces ipromog so:

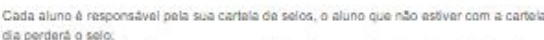
Gia perdara o selo,

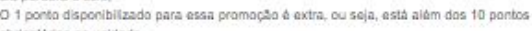
Q Que quer alzar osda itsm de oartals?

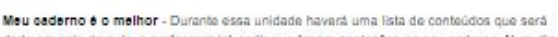

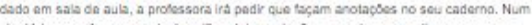
e estuenem cam at

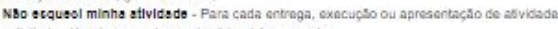

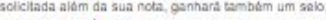

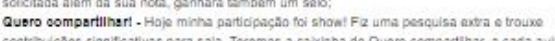

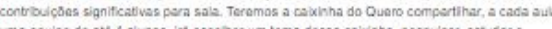

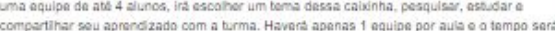
se 20 min para somsentactact.

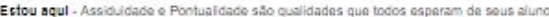

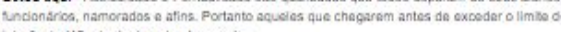

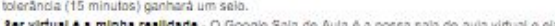

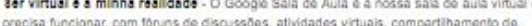

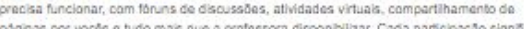

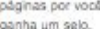

Figura 1. Cartela para colar os selos conquistados

Já conhecendo as turmas, por já terem sido alunos em anos anteriores, não foi necessário um estudo mais aprofundado para conhecer os perfis e seus gostos, consequentemente não foi difícil entender quais seriam os prêmios que mais os motivariam. 
VIII Congresso Brasileiro de Informática na Educação (CBIE 2019)

Anais dos Workshops do VIII Congresso Brasileiro de Informática na Educação (WCBIE 2019)

Os prêmios foram definidos atentando quais eram os hábitos mais comuns das turmas ou os seus anseios, hábitos esses negativos, os quais gostaria que fossem reconstruídos, assim, prêmios como a não entrega de uma atividade ou não assistir uma aula sem ônus, estavam dentre os brindes que o estudante poderia ganhar. O estudante passaria a ter esse direito caso cumprisse determinadas missões que estariam garantindo o direito de aprendizagem deles. Os brindes ficaram definidos da seguinte forma:

- ser liberad@ da entrega de uma atividade; (itens 1 ou 2)

- escolher o tipo de prova (objetiva ou aberta); (itens 1 ou 2 ou 3 ou 5)

- não assistir uma aula sem ônus; (itens 3 e 4)

- aumentar o nível de $\mathrm{XP}^{1}$ na disciplina (ganhar um ponto) - maior número de selos em todos os ítens.

Após a definição dos brindes, fora pensado nas missões, ou seja, o que os estudantes precisavam fazer para ganhar os selos. Missões como ter o apontamento no caderno, entregar a atividade na data determinada, pesquisar um assunto do componente curricular e compartilhar com a turma, chegar no horário da aula e participar das atividades virtuais foram norteadoras para que essas boas práticas fossem desenvolvidas nos estudantes. A cada uma delas realizadas ganhava-se um selo que era colado na cartela.

Ao juntar 5 (cinco) selos numa mesma categoria podia-se trocar por um dos brindes elencados acima e, consequentemente, o estudante ganhava o status daquela categoria. Assim, o estudante que juntasse os cinco selos na categoria Meu caderno é o melhor, além de se tornar O/A Rei/Rainha do Caderno Organizado ou na categoria Não esqueci minha atividade e se tornar O/A Entregador(a) de atividades, ainda ganha como brinde Ser liberado(a) da entrega de uma atividade.

Para além dessas missões, os estudantes também podiam coletar selos extras e conquistar o status de Queridinho(a) da professora. Tais selos podem ser colecionados quando o estudante não era chamado a atenção por estar conversando fora de hora ou usando o celular de maneira inadequada, dentre outras atitudes de cordialidade que gostaria de desenvolver nos estudantes.

\footnotetext{
${ }^{1}$ gíria e acrônimo da palavra Experience em inglês; utilizada nos games e significa Experiência, quando o jogador acumula Pontos de Experiência pode lhe render benefícios ao longo do jogo.
} 
VIII Congresso Brasileiro de Informática na Educação (CBIE 2019)

Anais dos Workshops do VIII Congresso Brasileiro de Informática na Educação (WCBIE 2019)

\section{Resultados e Discussões}

Ao apresentar a proposta para as turmas fora lhes pedido que pensassem nas seguintes possibilidades:

- Que tal ganhar XP por entregar as atividades na data marcada?

- Ou, quem sabe, ganhar um brasão por ter chegado no horário?

- Ou ganhar um like por ter pesquisado mais sobre o assunto dado na aula?

- E se, ao final, quem tiver mais likes pode escolher entre fazer uma prova objetiva ou aberta?

Os estudantes ficaram entusiasmados, querendo logo saber como isso seria possível. Ao apresentar a cartela ficaram mais entusiasmados ainda e logo disseram que aceitavam a proposta. No dia seguinte, todos estavam com suas cartelas em mãos, chegando no horário e cobrando pelos selos.

Nesse período inicial foi observado o engajamento de $95 \%$ dos alunos envolvidos, principalmente nas missões de chegar no horário da aula e na entrega de atividades. Os resultados também foram positivos na missão Quero compartilhar, quando eles precisaram fazer pesquisas sobre assuntos do componente curricular, mas que não seriam contemplados durante as aulas. Porém a missão que exigia que os estudantes participassem das atividades desenvolvidas na sala de aula virtual, continuou incipiente.

Entretanto, ao longo da unidade (período em que estava vigorando a "promoção"), alguns estudantes não mantiveram a postura adotada no início, não dando mais importância para a conquista dos selos, situação também já observada por (Hamari et al. 2014). Os autores, em sua pesquisa, concluíram que a gamificação só tem efeito positivo no início e por um curto período.

$\mathrm{Na}$ tentativa de resgatar esses estudantes e, como todo jogo deve prever a possibilidade de ganho por parte do jogador, foi criado o que se chamou de "Maratona de Banco de Dados: em busca do selo perdido", (vide em http://bit.ly/2OsTouT) uma série de atividades e missões para que os estudantes conquistassem os selos não conseguidos no período da "promoção" e consequentemente as boas práticas desejadas. Foram propostas atividades diferenciadas e em curto período de tempo e foram, em quase sua totalidade, desenvolvidas na sala de aula virtual. 
VIII Congresso Brasileiro de Informática na Educação (CBIE 2019)

Anais dos Workshops do VIII Congresso Brasileiro de Informática na Educação (WCBIE 2019)

Os estudantes gostaram do ritmo que foi empregado à maratona, dizendo estar parecendo uma "gincana", pois em algumas atividades nem todos ganhavam os selos, mas apenas os primeiros, as com mais acertos ou mais significativas. Durante esse período muitos retomaram ao processo de engajamento que tinha se iniciado. E assim, além do engajamento, conseguimos a participação ativa na sala de aula virtual e o aprendizado de conteúdos importantes no componente de Banco de Dados.

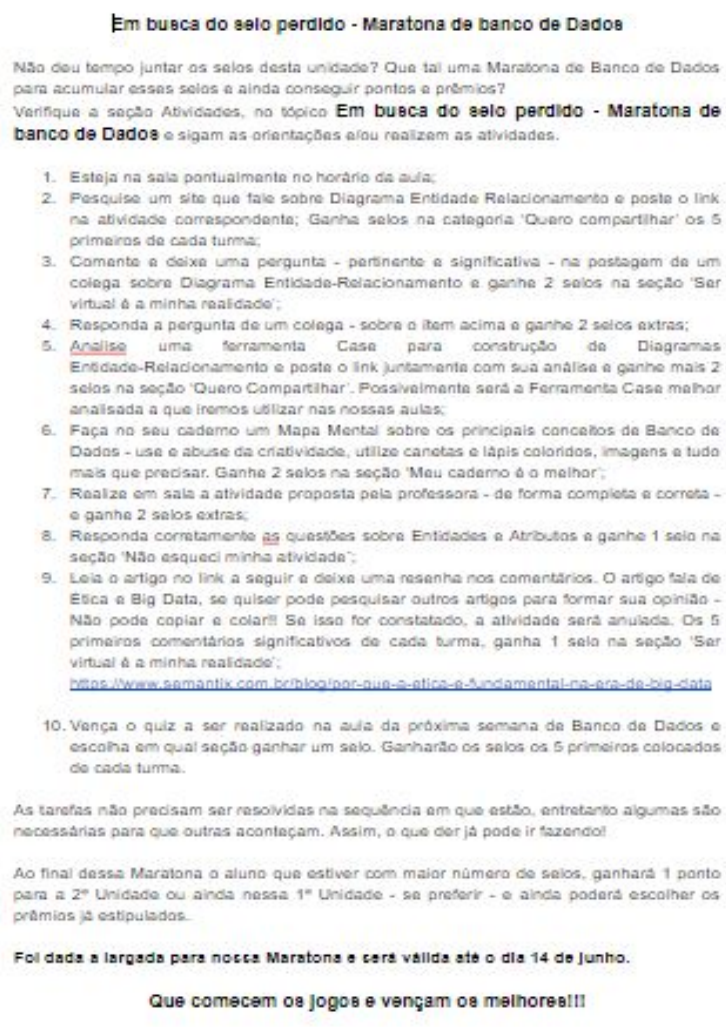

Figura 2. Orientações para a Maratona de Banco de Dados

Não obstante, das três turmas, por volta de 56 alunos envolvidos, apenas uma turma, com 22 estudantes, se destacou durante toda a execução da proposta, tendo grande aproveitamento por parte dos estudantes que ganharam todos os brindes. 12 ganharam os 4 brindes ofertados e 10 ganharam entre 2 a 3 brindes. Na segunda turma, dos 8 estudantes, apenas 3 (três) se destacaram, ganhando os 4 brindes. Na terceira turma, com 23 estudantes, não houve nenhum destaque significativo, apenas 5 alunos ganharam 1 brinde. Esse fato já havia sido observado por Berkling \& Thomas (2013), ao concluir que estudantes não são necessariamente jogadores, ao perceber que no seu trabalho apenas $18 \%$ dos estudantes jogavam diariamente. No caso em questão, acredito ter falhado em não verificar quantos 
VIII Congresso Brasileiro de Informática na Educação (CBIE 2019)

Anais dos Workshops do VIII Congresso Brasileiro de Informática na Educação (WCBIE 2019)

desses alunos tinham por hábito jogar e quais as suas preferências.

\section{Considerações Finais}

Este artigo apresentou uma síntese de uma experiência pedagógica de uma proposta de gamificação aplicada como estratégia de aprendizagem ativa em turmas do ensino médio profissionalizante.

O trabalho demonstrou que a ludicidade foi importante para o engajamento e em qualquer fase da vida humana. Os ganhos com a gamificação estão para além dos jogos enquanto estratégia de aprendizagem, pois possibilita que qualquer conteúdo da grade curricular possa ser gamificado, ou seja, que pode servir de base para incluir os mecanismos e dinâmicas dos jogos e tornar tanto o aprendizado quanto o ensino mais dinâmico e prazeroso.

É fato que é um desafio conseguir o engajamento perene dos estudantes, principalmente os do Ensino Médio, por se tratarem de adolescentes, onde se é sabido que todos passam por transformações. Entretanto, apesar de percebido o engajamento por pouco mais de $50 \%$ dos estudantes envolvidos, aqueles que aproveitaram a experiência mantiveram as boas práticas de disciplina e comprometimento consolidadas, levando isso, inclusive para outros componentes curriculares. Foi observado que esses estudantes tiveram um rendimento maior e melhor no componente curricular de Banco de Dados, onde foi proposta a gamificação e também no de Linguagem de Programação, em que, ao final do semestre conseguiram concluir com êxito uma proposta de software, proposta essa, que não havia se concretizado em outro momento. Acredita-se que o engajamento deles para com o aprendizado tenha favorecido essa questão. Outros professores também comentaram a mudança no comprometimento dos estudantes.

Um ganho perceptível foi o engajamento dos estudantes no cumprimento das missões. Entretanto, dentre os pontos ainda a serem investigados, observa-se que é preciso uma análise mais consistente sobre a turma em que será aplicada a gamificação, entender quais são os tipos de jogos, desafios e brindes que os motivam; investigar qual a interface é mais apropriada, seja ela desplugada como a cartela criada ou se essa precisa ser desenvolvida em meio digital, importante também compreender o período em que deverá ser aplicada para que não percam o interesse. 
VIII Congresso Brasileiro de Informática na Educação (CBIE 2019)

Anais dos Workshops do VIII Congresso Brasileiro de Informática na Educação (WCBIE 2019)

Para trabalhos futuros, pretende-se investigar novas experiências deste trabalho em outras turmas de Ensino Médio, com perspectiva científicas. Pretende-se criar uma arte para a "cartela", uma vez que somos visuais; usar selos personalizados, pois os selos utilizados tinham figuras aleatórias e infantis como frutas e animais, o objetivo era apenas marcar qual das missões o estudante tinha cumprido. Tem-se também a proposta de premiar os estudantes com bottons quando atingirem determinados status e criar um mapa que demonstre o progresso dos estudantes. Outra proposta é criar cartelas menores, com missões e tempos também menores, por perceber que quando demorado os estudantes perdem o interesse, como acontecido em algumas turmas.

Por fim, frente à gamificação, cabe ao professor compreender que não se trata de criar um app ou game; a difícil tarefa de compreender a distinção entre trabalhar com jogos/games/gamificação visando a ressignificação da mera ilusão do fazer diferente ao usar jogos e suas mecânicas na sala de aula, a escolha não deve ser aleatória e deve ter objetivos claros, o jogar e a produção de conhecimentos devem ser atos indissociáveis.

\section{Referências}

Albornoz, Suzana Guerra. Jogo e trabalho: do homo ludens, de Johann Huizinga, ao ócio criativo, de Domenico De Masi. Cad. psicol. soc. trab., São Paulo, v. 12, n. 1, p. 75-92, jun. $2009 \quad$ Disponível em $<$ http://pepsic.bvsalud.org/scielo.php?script=sci_arttext\&pid=S1516-37172009000100007 $\& \operatorname{lng}=$ pt\&nrm=iso $>$. acessos em 05 out. 2019.

Alves, L.R.G. Games: Desenvolvimento E Pesquisa No Brasil. In: Nascimento, Ad., And Hetkowski, Tm., Orgs. Educação E Contemporaneidade: Pesquisas Científicas E tecnológicas. Salvador: EDUFBA, 2009, pp. 376-394. ISBN 978-85-232-0872-1. Available from SciELO Books.

Berkling, K. and Thomas, C. (2013). Gamification of a software engineering course and a detailed analysis of the factors that lead to it's failure. In Interactive Collaborative Learning (ICL), 2013 International Conference on, pages 525-530. IEEE.

Da Silva, J. A. L., Oliveira, F. C. S. \& Martins, D. J. S. (2017). Storytelling e gamificação como estratégia de motivação no ensino de programação com Python e Minecraft.

Fardo, M. L. (2013). A gamificação,aplicada em ambientes de aprendizagem. RENOTE, 11(1).

Fiqueiredo, M., Paz, T., and Junqueira, E. (2015). Gamificação e educação: um estado da arte das pesquisas realizadas no brasil. In Anais dos Workshops do Congresso Brasileiro de Informática na Educação, v. 4, p. 1154. 
VIII Congresso Brasileiro de Informática na Educação (CBIE 2019)

Anais dos Workshops do VIII Congresso Brasileiro de Informática na Educação (WCBIE 2019)

Filho, Roberto; Silva, Henrique; Inocêncio, Ana Carolina. Um Mapeamento Sistemático sobre Fatores que Podem Influenciar na Eficiência da Gamificação. Brazilian Symposium on Computers in Education (Simpósio Brasileiro de Informática na Educação - SBIE), [S.1.], p. 506, out. 2018. ISSN 2316-6533. Disponível em: $<$ https://www.br-ie.org/pub/index.php/sbie/article/view/8007/5701>. Acesso em: 05 out. 2019. doi:http://dx.doi.org/10.5753/cbie.sbie.2018.506.

Guedes, A (2018). Projeto de Aprendizagem Gamificado: Um Relato de Experiência. Anais do Simpósio Brasileiro de Informática na Educação (SBIE) p. 635-644. Disponível em: $<$ https://www.br-ie.org/pub/index.php/sbie/article/view/8022>. Acesso em: 05/10/2019.

Hamari, J., Koivisto, J., and Sarsa, H. (2014). Does gamification work? - a literature review of empirical studies on gamification. In: System Sciences (HICSS), 47th Hawaii International Conference on, p. 3025-3034.

Huizinga, J. (1999). Homo ludens: o jogo como elemento da cultura. Perspectiva: São Paulo.

Silva, J. B.; Sales, G. L.; Castro, J. B. (2019) Gamificação como estratégia de aprendizagem ativa no ensino de Física. Rev. Bras. Ensino Fís., São Paulo, v. 41, n. 4, Disponível em $<$ http://www.scielo.br/scielo.php?script=sci_arttext\&pid=S1806-11172019000400502\&ln $\mathrm{g}=\mathrm{en} \& \mathrm{nrm}=\mathrm{iso}>$. Acessado em 06/10/2019.

Silva, A. P.; Martinz, V. F.; Dutra, C.; Machado, T. L. A. ; Araújo Luiz F. A. (2015) Gamificação para melhoria do engajamento no ensino médio integrado. SBC Proceedings of SBGames. ISSN: 2179-2259. Disponível em $<$ https://www.sbgames.org/sbgames2015/anaispdf/cultura-full/146993.pdf> Acesso em: 05 out 2019 ,

Yu-kai Chou: Gamificação e Design Comportamental. Disponível em $<$ https://yukaichou.com/> Acesso em 06 out 2019.

Vygotsky, Lev Semenovich. A formação social da mente. 6. ed. São Paulo: Martins Fontes, 1998.

Werbach, K.; Hunter, D. For the Win: How Game Thinking Can Revolutionize Your Business. Wharton Digital Press, Pennsylvania, 2012. 1. Edition. Philadelphia: Wharton Digital Press, 2013. Disponível em: . Acessado em: XX jan. 2016. 